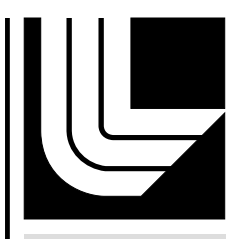

LLNL-TR-504131

LAWRENCE LIVERM ORE NATIONAL LABORATORY

Input to LLE annual report

H. Chen

October 10, 2011 
This document was prepared as an account of work sponsored by an agency of the United States government. Neither the United States government nor Lawrence Livermore National Security, LLC, nor any of their employees makes any warranty, expressed or implied, or assumes any legal liability or responsibility for the accuracy, completeness, or usefulness of any information, apparatus, product, or process disclosed, or represents that its use would not infringe privately owned rights. Reference herein to any specific commercial product, process, or service by trade name, trademark, manufacturer, or otherwise does not necessarily constitute or imply its endorsement, recommendation, or favoring by the United States government or Lawrence Livermore National Security, LLC. The views and opinions of authors expressed herein do not necessarily state or reflect those of the United States government or Lawrence Livermore National Security, LLC, and shall not be used for advertising or product endorsement purposes.

This work performed under the auspices of the U.S. Department of Energy by Lawrence Livermore National Laboratory under Contract DE-AC52-07NA27344. 


\section{Input to LLE FY11 Annual Report}

In FY2011, an LLNL/LLE/NRL team performed a Laboratory Basic Science experiment on the OMEGA EP laser system to study positron production during high intensity laser interactions with high $\mathrm{Z}$ targets. This experiment was a follow-on to those of April 2009 and August 2010. In the previous experiments, a record number of positrons was produced using the $1 \mathrm{~kJ}, 10 \mathrm{ps}$ OMEGA EP backlighter interacting with a $1 \mathrm{~mm}$ thick $\mathrm{Au}$ target [1]. It was deduced that a non-neutral pair plasma was made in those shots [2]. In FY2011, thanks to the facility improvements the laser energy was extended to $1400 \mathrm{~J}$ for the Backlighter beam. The FY 2011 experiments had two main objectives; to measure the energy scaling of the positron generation and to measure angular divergence of the electron-positron jets creased. The preliminary results are shown in Figure 1 and Figure 2, for the energy scaling and angular divergence, respectively. A seemly faster increase in positron number was observed once the laser energy exceeded $1 \mathrm{~kJ}$. The electron-positron jet has a very narrow angular divergence of about 6-7 degrees. On these shots, the Gamma-Crystal spectrometer (with the energy coverage between $40 \mathrm{keV}$ to $700 \mathrm{keV}$ ) that was modified to reduce the background radiation was further tested. Annihilation of electron positron radiation was not observed, perhaps due to low efficiency of the crystal as well as the detector.

Positron research has extended over diverse fields from particle physics and astrophysics to medical application. This often requires the production of large numbers of positrons on a short time scale, which has been difficult to supply. The new OMEGA EP results could alter the direction of the quest of establishing a laser-produced positron source for research in these fields.

[1] Chen, Hui, Wilks, S, Meyerhofer, D. D, et al., Relativistic Quasi-monoenergetic Positron Jets From Intense Laser-Solid Interactions Physical Review Letter 105, 015003 (2010).

[2] Chen, Hui, Meyerhofer, D. D. et al., Towards laboratory produced relativistic electron-positron pair plasmas, High Energy Density Physics, 7, 225 (2011)

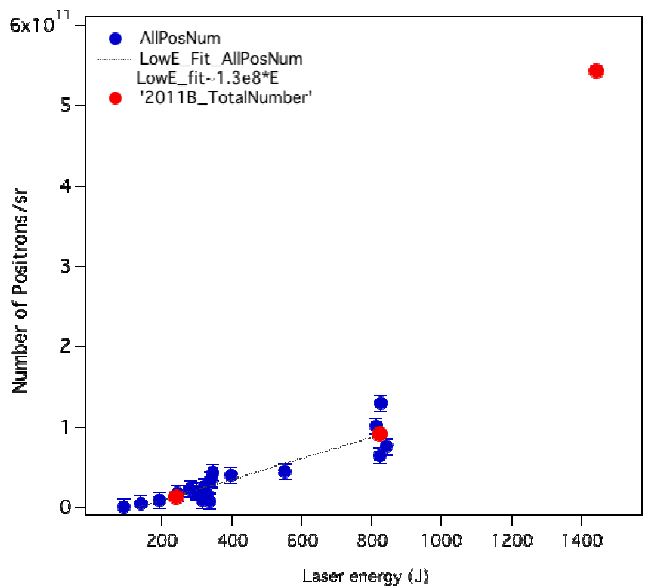

Figure 1. Positron number as a function of laser energy. Red dots are form FY11 EP experiments. Blue dots are all previous data.

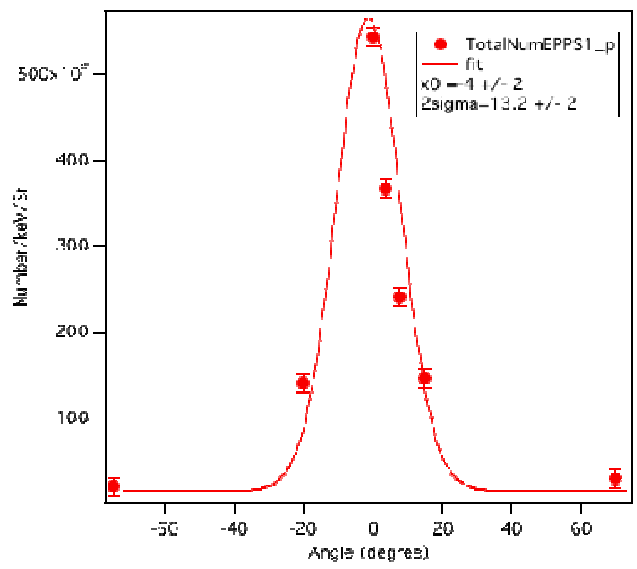

Figure 2. Angular divergence of the positron jet measured from FY11 EP experiments. 